\title{
Tuberculoma in the Medulla Oblongata and Medulla Spinalis: Two Case Reports
}

\author{
Salih Gülşen, Hakan Caner \\ Department of Neurosurgery, Başkent University Faculty of Medicine, Ankara, Turkey
}

\begin{abstract}
Background: Central nervous system tuberculosis remains a prevalent problem in developing countries. Also, this disease has been an important problem in developed countries due to the increased incidence of acquired immunodeficiency syndrome. Tuberculosis of the central nervous system is seen in $10 \%$ of immunocompetent patients with primary tuberculosis.

Case Report: We report two patients with tuberculoma in the central nervous system. The first case had a lesion located in the medulla oblongata, and the second case had a lesion in the medulla spinalis between the $5^{\text {th }}$ cervical and $1^{\text {st }}$ thoracic vertebral level. Both of these patients underwent surgery.

Conclusion: CNS tuberculomas may not always show typical magnetic resonance imaging (MRI) signs, but when a neurosurgeon encounters a brownyellow rubber-like lesion that is easily extirpated from the glial tissue, tuberculoma should be considered; anti-tuberculous and corticosteroid therapy should be initiated as soon as possible to prevent meningitis and the immune-mediated destructive effects of tuberculosis on the CNS. Whether or not anti-tuberculous therapy is continued can be decided upon by following definitive pathologic diagnosis.
\end{abstract}

Key Words: Medulla oblongata, spinal cord, meningitis, oedema, tuberculomas

Received: 18.02.2013

Accepted: 24.05 .2013

\section{Introduction}

Tuberculosis occurs worldwide, and is an important health problem in developing countries $(1,2)$. Also, tuberculosis with human immunodeficiency virus (HIV) co-infection is an important health problem in developed countries due to the increased incidence of HIV positivity (1-3). Central nervous system (CNS) involvement occurs in close to $10 \%$ of immunocompetent patients with tuberculosis $(1,2)$. Tuberculomas occur in the cerebral hemispheres and basal ganglia in adults, and in the cerebellar hemispheres in children; brainstem and spinal lesions are rare (4). Here, we present 2 cases of tuberculoma in the CNS. The first case had a lesion located in the medulla oblongata, and the second had a lesion in the medulla spinalis.

\section{Case 1}

A 78 year-old female presented with a 4-month history of progressive left-sided ataxia and weakness. She was unable to walk without assistance. Routine investigations, including $\mathrm{CBC}$, liver and kidney function tests, and chest X-ray were normal. T1-weighted cranial MRI showed a 10×12×10 mm intramedullary lesion in the medulla oblongata that exhibited diffuse contrast enhancement following administration of Gadolinium-diethylene triamine pentaacetic acid (GD-DTPA), but no perilesional vasogenic oedema (Figures $1 \mathrm{a}$ and $1 \mathrm{~b}$ ). We performed suboccipital craniotomy with a telovelar approach to visualise the medulla oblongata which was expanded due to tuberculoma. Then, we incised this expanded region and found the tumour at a depth of about $2 \mathrm{~mm}$. The tumour was firm and brown-yellow in colour; it was easily dissected and completely excised (Figure 2). Histological examination of the specimen showed a granulomatous lesion containing multinucleated giant cells and inflammatory cells with caseous necrosis (Figure 3). Following the diagnosis of tuberculosis, anti-tuberculous chemotherapy was initiated. Three months post-surgery, the patient was able to walk without assistance and no longer had left-sided ataxia.

\section{Case 2}

A 42 year-old male presented with a 7-month history of loss of upper extremity strength. Finger abduction, flexion and extension, thumb abduction and opposition, wrist extension and flexion, and elbow flexion and extension were 4/5 on both sides. Deep tendon reflexes were increased and the patient had bilateral positive Babinski response. Lower extremity function was normal. Routine investigations, including $C B C$, liver and kidney function tests, and chest X-ray were normal. T1weighted sagittal plane spinal MRI with GD-DTPA showed a hyperintense intramedullary lesion in the medulla spinalis with diffuse contrast enhancement. This lesion was located between the $5^{\text {th }}$ cervical and $1^{\text {st }}$ thoracic vertebrae (Figure 4). Laminectomy between the $4^{\text {th }}$ cervical and $2^{\text {nd }}$ thoracic vertebrae was performed and the dura mater was opened. Then, we incised the medulla spinalis in the region of the expansion, and found the lesion at a depth of about $1 \mathrm{~mm}$. The tumour, which was firm, brown-yellow, and rubber-like in consistency, was extirpated from the glial tissue with some difficulty due to 

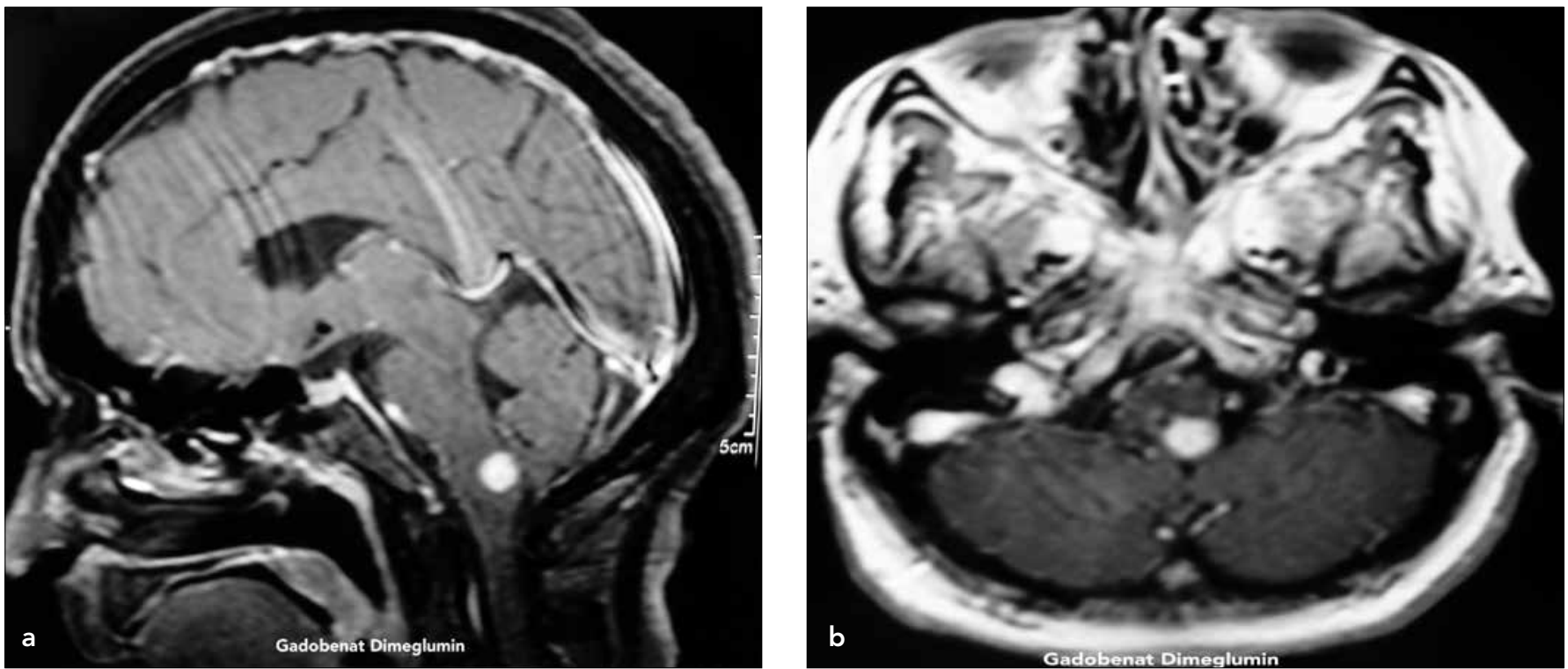

Figure 1. a, b. Sagittal plane post-contrast cranial T1-weighted MRI (a), Axial plane post-contrast cranial T1-weighted MRI, (b) show a coin-shaped, contrast-enhanced lesion in the medulla oblongata in Case 1.

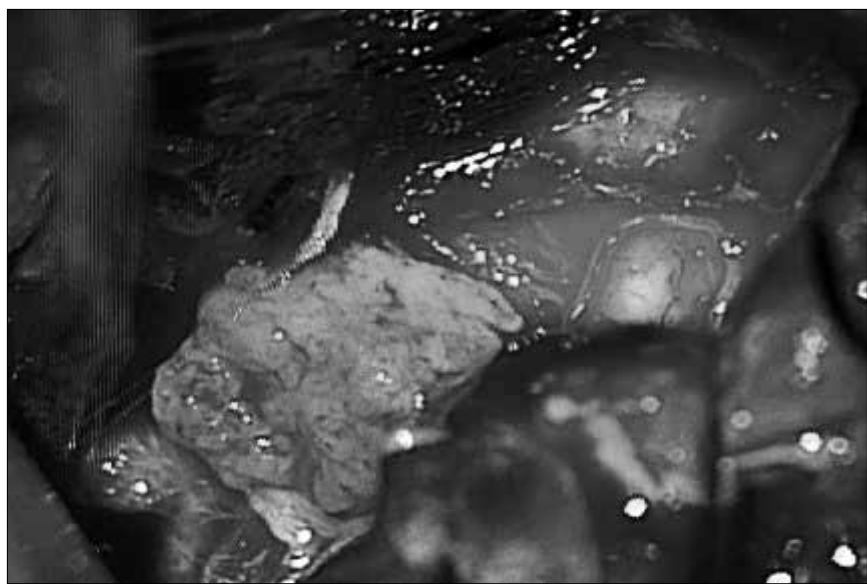

Figure 2. Intraoperative photograph showing the lesion that was extirpated from the adjacent glial tissue in Case 1.

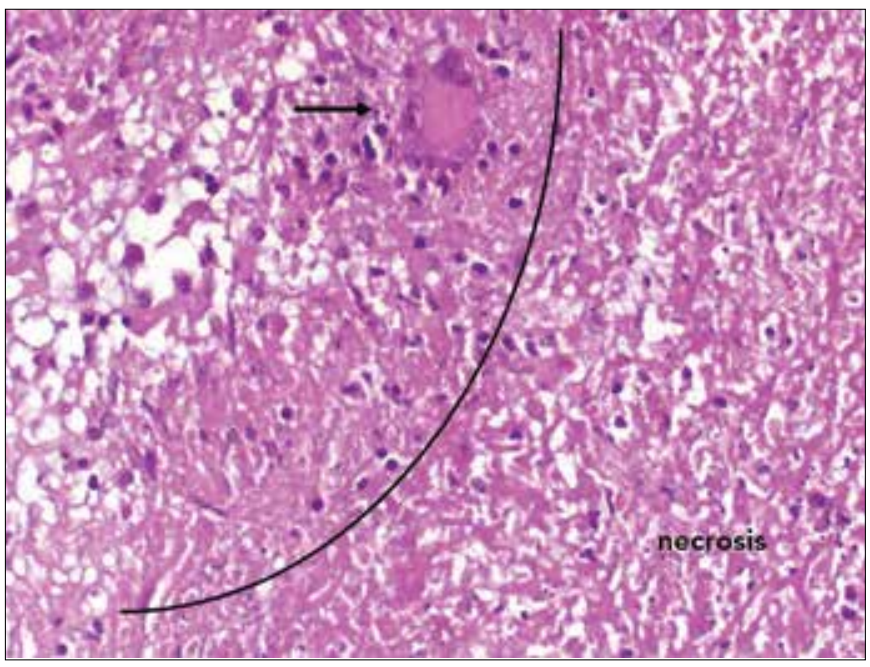

Figure 3. Histological examination showing the demarcation line of the caseous necrosis, epithelioid histiocytes, and Langerhans giant cells (arrow) in case 1 (H\&E, 400x).

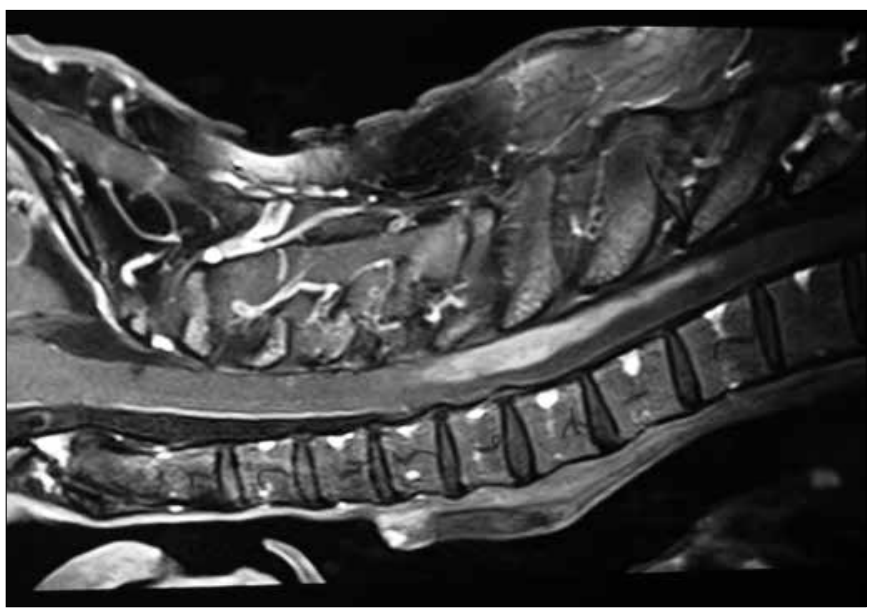

Figure 4. Sagittal plane post-contrast spinal T1-weighted MRI shows the contrast-enhanced lesion between the $5^{\text {th }}$ cervical and $1^{\text {st }}$ thoracic vertebrae in Case 2. Additionally, no oedema is seen, but the border between normal neural tissue and the lesion is remarkable.

adhesions to surrounding glial tissue. Histological examination of the specimen showed a granulomatous lesion containing multinucleated giant cells and inflammatory cells with caseous necrosis (Figure 5). Following the diagnosis of tuberculosis, anti-tuberculous chemotherapy was started. His neurological examination findings remained unchanged five months after the surgery.

\section{Discussion}

Tuberculosis of the CNS is relatively common in developing countries, but tuberculosis in the medulla spinalis and medulla oblongata is rarely seen $(5,6)$. CCT (Cranial computed tomography) and craniocervical MRI are effective tools for the diagnosis of CNS tuberculosis. Central calcification in a ring-enhancing lesion is known as the target sign, and is indicative of caseous 


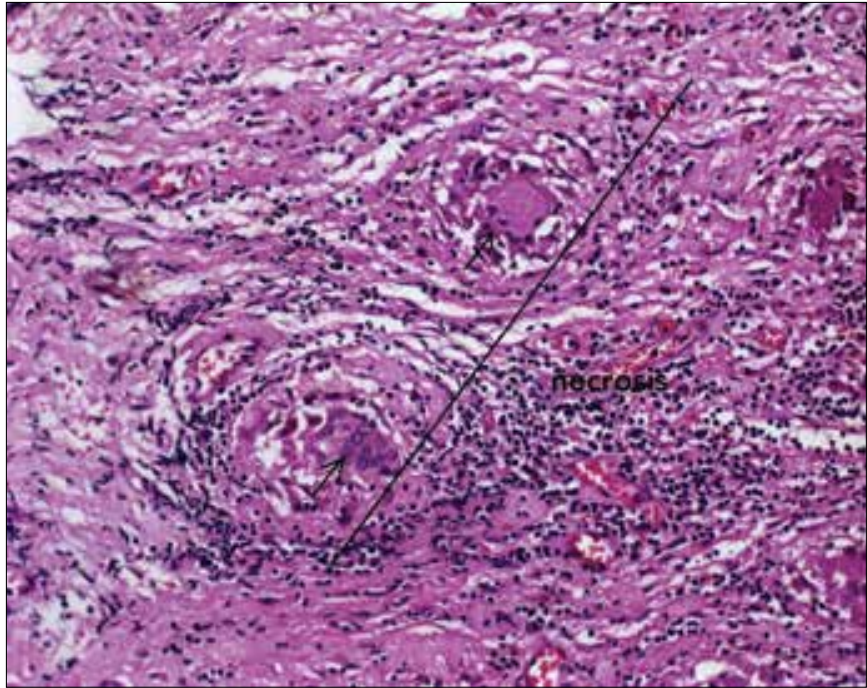

Figure 5. Histological examination shows the demarcation line of the caseous necrosis, epithelioid histiocytes, and Langerhans giant cells (arrows) in Case 2 (H\&E, 200x).

necrosis and tuberculoma; however, it is not pathognomonic for tuberculoma $(7,8)$. CCT has a high sensitivity, but low positive predictive value of only $33 \%$ for diagnosing CNS tuberculoma with the support of clinical symptoms and signs (9). Tuberculomas appear isodense (to grey matter) centrally on T1-weighted MRI and iso- to hypointense on T2-weighted MRI (10). Caseous necrosis appears as a central isointensity (or mixed iso- and hyperintensity) and a fibrous collagen capsule appears as a hyperintense rim on T1-weighted MRI. In addition, a second hypointense rim signal can be seen that corresponds to an outer layer of inflammatory infiltration (11). Dastur et al. (12) reported that only $8 \%$ of 74 patients with tuberculous paraplegia had intramedullary lesions. MacDonnell et al. (13) reported that the low brain:spinal cord tuberculoma ratio (42:1) was related to weight proportion. Tegeris et al. (14) reported a solitary tuberculoma in the medulla oblongata as a necropsy finding in 1958. In 1957, Halasy and Lehoczky (15) reported a case of tuberculoma located in the medulla oblongata that was cured with isoniazid. In addition, Aideeb (16) reported 2 cases of tuberculoma located at the junction of the medulla oblongata and the cervical spinal cord, both of which presented with intractable hiccups and mild to moderate neurological signs. Both patients were free of hiccups 1-5 months after anti-tuberculous chemotherapy.

Anti-tuberculous agents and steroids are the mainstay for the treatment of CNS tuberculosis $(3,17)$. Steroids reduce the mass effect of associated oedema in tuberculomas and limit immune-mediated progression of these lesions $(5,18)$. Large and solitary tuberculomas that do not respond to medical therapy and those that cause mass effect, midline shift, and hydrocephalus should be treated surgically; however, such surgery is associated with a high mortality rate due to postoperative meningitis and oedema (18). In addition, tuberculous abscesses are associated with a poor prognosis and rapid progression with fever, headache, and neurological signs; as such, the treatment of choice for tuberculous abscesses is always surgical extirpation followed by a full course of anti-tuberculous chemotherapy $(2,12,17)$.
Patients with tuberculomas rarely have symptoms of primary tuberculosis, such as fever, weight loss, and loss of appetite, because the absence of toxaemia is associated with an inability of the wall of a tuberculoma to permit absorption $(2,12)$. Tuberculomas may occur in any part of the nervous system due to the haematogenous spread of the tuberculous bacillus. Tuberculomas can cause signs of elevated intracranial pressure, including weakness, hemiparesis, ataxia, diplopia, headache, vomiting, and seizure, and some patients also have signs of extracranial tuberculosis (19). Seizure is one of the most frequently encountered symptoms and is a presenting symptom in $\leq 85 \%$ of patients with tuberculomas (12). Both of the presented cases had a negative history of tuberculosis, but both had some neurological symptoms, including ataxia, left-sided weakness, and loss of upper extremity strength. Case $1 \mathrm{had}$ a tuberculoma in the medulla oblongata and the lesion, in Case 2 , this was in the spinal cord. Both patients were treated surgically due to progressive symptoms and signs; however, cranial MRI in Case 1 and spinal MRI in Case 2 did not show any specific signs of tuberculoma. Preoperatively, the lesion in Case 1 was similar to an extraaxial metastatic lesion, and the lesion in the medulla spinalis in Case 2 was similar to an intraaxial glial tumour. The lesion in first case had an appearance similar that of metastatic lesion intraoperatively, because we were able to easily dissect the lesion from the surrounding glial tissue. The lesion in the second case was different from the first case, because it was attached to the surrounding tissue more than in the first case. However, we were able to dissect this lesion without causing any damage to the surrounding tissue. When we performed close examination of the dissected lesions were not similar to either metastatic or glial tumours. The lesion in both cases had a brown-yellow colour and the consistency of rubber. The diagnosis of tuberculomas is important, because direct surgical evacuation of tuberculomas is associated with a high mortality rate due to postoperative meningitis and oedema. Surgery, excision or biopsy, is generally performed when the diagnosis is in doubt or there is no response to medical therapy because of the high mortality rate $(19,20)$. The mortality rate associated with surgical treatment of tuberculomas without anti-tuberculous therapy is between $35 \%$ and $85 \%$ (19). Fortunately, the two presented patients did not develop oedema or meningitis post-surgery.

Although numerous researchers have described the MRI features of CNS tuberculomas, atypical cases still occur, such as the 2 presented cases that did not have MRI findings specific for tuberculomas. The lesion in Case 1 was similar to the metastatic lesion regarding its shape, but not similar regarding its location and lacking oedema in T1-weighted MRI. The lesion located in the spinal cord in Case 2 showed a diffuse contrast-enhanced intraaxial lesion within the spinal cord in T1-weighted MRI. This imaging feature also does not correspond with the imaging feature of the tuberculoma. In conclusion, CNS tuberculomas may not always show typical MRI signs, but when a surgeon encounters a brown-yellow rubberlike lesion that is extirpated from the glial tissue, tuberculoma should be suspected, and anti-tuberculous and corticosteroid therapy should be initiated as soon as possible to prevent meningitis and the immune-mediated destructive effects of 
tuberculosis on the CNS. Whether or not anti-tuberculous therapy is continued can be decided upon following the definitive pathologic diagnosis.

\section{Ethics Committee Approval: N/A.}

Informed Consent: Written informed consent was obtained from the patients.

Author contributions: Concept-S.G., H.C.; Design - S.G., H.C.; Supervision - S.G., H.C.; Resource - S.G., H.C.; Materials - S.G., H.C.; Data Collection\&/or Processing - S.G., H.C.; Analysis\&/or Interpretation - S.G., H.C.; Literature Search - S.G., H.C.; Writing - S.G., H.C.; Critical Reviews - S.G., H.C.

Conflict of Interest: The authors declared no conflict of interest.

Financial Disclosure: The authors declared no financial disclosure.

\section{References}

1. Centers for Disease control: TB elimination revisited: Obstacles, opportunities, and a renewed commitment. MMWR Morb Mortal Wkly Rep 1999;48:1-13

2. Udani PM, Parekh UC, Dastur DK. Neurological and related syndromes in CNS tuberculosis. Clinical features and pathogenesis. J Neurol Sci 1971;14:341-57. [CrossRef]

3. Bass JB Jr, Farer LS, Hopewell PC, O'Brien R, Jacobs RF, Ruben $F$, et al. Treatment of tuberculosis and tuberculosis infection in adults and children. American Thoracic Society and The Centers for Disease Control and Prevention. Am J RespirCrit Care Med 1994;149:1359-74. [CrossRef]

4. Dastur DK, Lalitha VS, Prabhakar V. Pathological analysis of intracranial space -occupying Lesions in 1000 cases including children. Part 1.Age sex and pattern; and the tuberculomas. J Neurol Sci 1968;6:575-92. [CrossRef]

5. Citow JS, Ammirati M. Intramedullary tuberculoma of the spinal cord. Case report. Neurosurg 1994;35:327-30. [CrossRef]

6. Rao GP. Spinal intramedullary tuberculous lesion: medical management.Report of four cases. J Neurosurg 2000;93:137-41.
7. Bargalló J, Berenguer J, García-Barrionuevo J, Ubeda B, Bargalló N, Cardenal C, et al. The "target sign": is it a specific sign of CNS tuberculoma? Neuroradiology 1996;38:547-50.[CrossRef]

8. Welchman JM. Computerised tomography of intracranial tuberculomata. Clin Radiol 1979;30:567-73. [CrossRef]

9. Selvapandian S, Rajshekhar V, Chandy MJ, Idikula J. Predictive value of computed tomography-based diagnosis of intracranial tuberculomas. Neurosurg 1994;35:845-50. [CrossRef]

10. Gupta RK, Jena A, Singh AK, Sharma A, Puri V, Gupta M. Role of magnetic resonance (MR) in the diagnosis and management of intracranial tuberculomas. Clin Radiol 1990;41:120-7. [CrossRef]

11. Kim TK, Chang KH, Kim CJ, Goo JM, Kook MC, Han MH. Intracranial tuberculoma: comparison of MR with pathologic findings. Am J Neuroradiol 1995;16:1903-8.

12. Dastur HM. Diagnosis and neurosurgical treatment of tuberculous disease of the CNS. Neurosurg Rev 1983;6:111-17. [CrossRef]

13. MacDonnell AH, Baird RW, Bronze MS. Intramedullary tuberculomas of the spinal cord: case report and review. Rev Infect Dis 1990;12:432-39. [CrossRef]

14. Tegeris AS. Solitary tuberculoma of the medulla oblongata; case report. Pediatrics 1958;21:370-4.

15. Halasy M, Lehoczky T. Case of tuberculoma of medulla oblongata cured by isoniazid. Orv Hetil 1957:10:5- 6 .

16. Deeb Al SM, Sharif H, al Moutaery K, Biary N. Intractable hiccup induced by brainstem lesion. J Neurol Sci 1991;103:144-50. [CrossRef]

17. Bagga A, Kalra V, Ghai OP. Intracranial tuberculoma-evaluation and treatment. Clin Pediatr 1998;10:487-90.

18. Artico M, De Caro GM, Carloia S, Salvati M, D’Ambrosio M, Delfini R. Advances in diagnosis, treatment and prognosis of intracerebraltuberculomas in the last 50 years. Report of 21 cases. Neurochirurgie 1999;45:129-33.

19. Arseni $C$. Two hundred and one cases of intracranial tuberculoma treated surgically. J Neurol Neurosurg Psychiatry 1958;21:308-11. [CrossRef]

20. Awada A, Daif AK, Pirani M, Khan MY, Memish Z, Al Rajeh S. Evolution of brain tuberculomas under standard antituberculous treatment. J Neurol Sci 1998;156:47-52. [CrossRef] 